\title{
Resilience, Leadership and Work Engagement: The Mediating Role of Positive Affect
}

\author{
Zhen Wang' ${ }^{1}$ Chaoping $\mathrm{Li}^{2} \cdot$ Xupei $\mathrm{Li}^{3}$
}

Accepted: 18 March 2016/Published online: 21 September 2016

(C) Springer Science+Business Media Dordrecht 2016

\begin{abstract}
This study examines the influence of resilience and transformational leadership on work engagement, and it investigates the mediating effect of positive affect. A total of 422 employees at a large IT company participated the survey. Participants completed established measures of resilience, transformational leadership, positive affect, and work engagement. The results indicate that resilience and transformational leadership are positively related to work engagement. Structural equation modeling analysis shows that positive affect partially mediates the relationships between resilience, transformational leadership, and work engagement. Theoretical contributions, practical implications, and future research directions are discussed.
\end{abstract}

Keywords Positive affect · Resilience - Transformational leadership · Work engagement

\section{Introduction}

Recently, positive psychology has become an emerging and prevailing area of psychological research (Peterson 2006; Seligman and Csikszentmihalyi 2000). Subjective wellbeing, which refers to individual's cognitive and affective evaluations of his or her life

Chaoping Li

lichaoping@mparuc.edu.cn

Zhen Wang

wangz@ruc.edu.cn

Xupei Li

lixupei@163.com

1 School of Labor and Human Resources, Renmin University of China, Zhongguancun Street 59, Haidian District, Beijing 100872, China

2 School of Public Administration and Policy, Renmin University of China, Zhongguancun Street 59, Haidian District, Beijing 100872, China

3 Institute of Psychology, Chinese Academy of Sciences, 16 Lincui Road, Chaoyang District, Beijing 100101, China 
(Diener 2000), is a central concern in positive psychology and occupational health. Work comprises a significant portion of an individual's life, and thus, engagement at work plays an important role when employees evaluate their life. Specifically, researchers have found that work engagement is positively related to job satisfaction and positive affect (Sonnentag et al. 2008). Studies also consistently indicate that work engagement is positively related to mental and physical health (Bakker et al. 2011). Thus, work engagement is likely the oldest and most common construct of workplace well-being (Yan and Su 2013).

Although there are different definitions of work engagement, Schaufeli and colleagues' definition is widely accepted (Bakker et al. 2011). Work engagement is most often defined as a positive, fulfilling, affective-motivational, work-related state characterized by vigor, absorption, and dedication (Schaufeli and Bakker 2004). Vigor refers to individuals' high levels of energy, willingness to invest significant effort in their job, and persistence despite difficulties. Dedication refers to individuals' finding that their work makes them feel significant, inspired, enthusiastic, challenged, and proud. Absorbed workers are completely concentrated on and happily immersed in tasks, so that time passes quickly and they find it difficult to detach themselves from the work (Schaufeli and Bakker 2004). Previous research has indicated that highly engaged workers, who are vigorous, dedicated and absorbed, are better able to cope with work difficulties and demands (Schaufeli and Bakker 2004). Because work engagement is beneficial to both workers and organizations, it is important to explore ways to increase workplace engagement.

An overarching framework for analyzing work-engagement antecedents is the job demands-resources (JD-R) model, which suggests that job resources and personal resources promote work engagement (Bakker and Demerouti 2008). Job resources are the physical, social, and organizational aspects that can reduce job demands, foster goal achievement, and stimulate personal growth (Bakker and Demerouti 2007). Typical job resources that enhance work engagement include social support, autonomy, and skill variety (Crawford et al. 2010). In addition to job resources, personal resources can be important predictors of work engagement. Studies have found psychological capital, which refers to an individual's positive psychological state of development, positively predicts work engagement (Xanthopoulou et al. 2007). In summary, job resources and personal resources are instrumental for the achievement of work goals and the satisfaction of basic psychological needs; thus, they facilitate work engagement.

Resilience is an important personal resource (Luthans et al. 2007). In positive psychology, resilience refers to positive coping and adaptation in the face of significant risk or adversity (Masten 2001). Although many studies have focused on the resilience of children and older individuals, few have focused on workplace resilience (Siu et al. 2009). In the workplace, Luthans (2002) defined resilience as "the positive psychological capacity to rebound, to 'bounce back' from adversity, uncertainty, conflict, failure or even positive change, progress and increase responsibility" (Luthans 2002, p. 702). Thus, we suspected that highly resilient individuals have more personal resources and are more likely to be engaged at work.

In terms of job resources, leadership is a critical environmental factor that may affect work engagement. Positive psychology and positive organizational behavior studies recognize that leadership is extremely important for generating positive well-being (Seligman et al. 2005). Thus, scholars call for additional research and attention regarding the relationship between positive forms of leadership, such as transformational leadership, and positive employee characteristics, such as work engagement (Zhu et al. 2009). Transformational leaders promote subordinates' intrinsic motivation, show concern for their needs, and provide work support to broaden their individual responsibilities for assuming greater 
challenges. Therefore, we expect that transformational leadership enhances work engagement.

Furthermore, positive affect may mediate the relationships between resilience, transformational leadership, and work engagement. Positive affect refers to high positive activation, including enthusiasm, alertness, and excitement (Watson et al. 1999). Those positive emotions generate long-term personal resources such as well-being. Indeed, a meta-analysis found that high positive affect predicted higher job satisfaction, greater organizational commitment, and lower burnout (Thoresen et al. 2003). According to the broaden-and-build theory (Fredrickson 2001), positive emotions broaden individuals' momentary thought-action repertoires, enhance their psychological resources, decrease their distress, and promote their creative ideas and prosocial actions (Fredrickson et al. 2003). Thus, individuals with high positive affect are more inclined to be engaged with their work. Furthermore, highly resilient individuals cope more successfully with stress and negative events and therefore have high levels of positive affect. Moreover, transformational leadership has an intense emotional component (Bass 1985). Transformational leaders may elicit feelings of happiness and enthusiasm in their followers (Bono et al. 2007) by attending to and supporting their needs and helping them cope with stressors, in turn promoting positive affect. Therefore, we hypothesized that positive affect mediates the relationship between resilience, transformational leadership, and work engagement.

\section{Method}

\subsection{Participants and Procedure}

We collected data from a large IT company that provides mobile communication service in southeast China. We distributed surveys to 438 fulltime employees and received 422 completed questionnaires with usable information, for a response rate of $96.34 \%$. These employees are sales workers in retail outlets and have frequent face-to-face interaction with customers. In terms of demographic variables, $59.34 \%$ of participants were male, and the mean age for the sample was 28.63 years $(S D=6.04)$. The average tenure was 73.96 months. Regarding education, $32.23 \%$ of participants had completed high school, $35.31 \%$ had completed college, $30.10 \%$ had bachelor's degrees, and $2.36 \%$ had master's degrees.

Two research assistants administered the survey in the company's training room. Before we conducted the survey, we obtained informed written consent from all participants. Employees completed a self-reported measure of resilience, transformational leadership, positive affect, work engagement, and demographic variables. The completed questionnaires were returned directly to the researchers on site. Anonymity and confidentiality were assured in the cover letter and at the beginning of each survey section. The entire process took approximately $15 \mathrm{~min}$.

Because the scales were originally developed in English, we followed Brislin's (1980) procedure to translate scales from the original English version into Chinese. First, two bilingual researchers translated the questionnaires from English into Chinese. Then, two different bilingual scholars translated the questionnaires back into English. A pilot study was also conducted to ensure that participants could understand the survey items correctly. 


\subsection{Measures}

\subsubsection{Resilience}

Resilience was measured with the 9-item resilience scale developed by Siu and colleagues (2009). Respondents used a 5-point Likert-type scale from $1=$ strongly disagree to $5=$ strongly agree. Sample items are "I have high capacity for facing adversity" and "In really difficult situations, I feel able to respond in positive ways." In the present study, the Cronbach's $\alpha$ was .79.

\subsubsection{Transformational Leadership}

Transformational leadership was measured with the transformational leadership behavior inventory (TLI; Podsakoff et al. 1990). Respondents used a 5-point Likert-type scale from $0=$ strongly disagree to $4=$ strongly agree. The scale has 23 items and measures six dimensions: articulating a vision, providing an appropriate model, fostering the acceptance of group goals, having high performance expectations, providing individualized support, and providing intellectual stimulation. The first three dimensions-articulating a vision, providing an appropriate model, and fostering the acceptance of group goals-are highly correlated. Therefore, the three factors were combined to represent the "core transformational leadership" construct (MacKenzie et al. 2001). As such, transformational leadership has four dimensions. For the purpose of the current study, the four dimensions represent indicators of the latent variable "transformational leadership". Sample items are "My leader articulates a vision" and "My leader considers my personal feelings before acting". In this study, the Cronbach's $\alpha$ was .92 .

\subsubsection{Positive Affect}

Positive affect was measured using the Positive and Negative Affect Schedule (PANAS), developed by Watson et al. (1988). The 10 items measuring positive affect were used in the present study. Participants rated each item on a 7-point scale from $0=$ not at all to $6=$ extremely to indicate how extensively they experienced a particular emotion in the prior few weeks. In this study, the Cronbach's $\alpha$ was .86.

\subsubsection{Work Engagement}

Work engagement was measured using the Utrecht Work Engagement Scale (UWES) developed by Schaufeli and colleagues (2002). Respondents rated the items on a 5-point Likert-type scale from $1=$ strongly disagree to $5=$ strongly agree. The scale has three dimensions: vigor, dedication, and absorption. Vigor is measured with 6 items, dedication with 5 items, and absorption with 6 items. Sample items are "At my job I feel strong and vigorous", "I am enthusiastic about my job" and "When I am working, I forget everything else around me." For the overall work engagement scale, the Cronbach's $\alpha$ is .90 .

\subsection{Data Analysis}

SPSS 17.0 was used for descriptive statistics and for calculating correlations among variables. Regarding structural equation modeling (SEM), we used a two-step approach 
(Anderson and Gerbing 1988). First, the measurement model was tested to examine how well the indicators represented each of the four latent variables. If the measurement model was acceptable, the structural model was tested. To control for inflated measurement errors from multiple indicators, we created three item parcels each for resilience and positive affect. For transformational leadership, we used the four dimensions as the indicators. Similarly, for work engagement, we used the three dimensions as the indicators.

AMOS 17.0 was used to conduct SEM analysis. Following previous recommendations (Hu and Bentler 1999), we used the Chi-square $\left(\chi^{2}\right), \chi^{2} / d f$, the root mean square error of approximation (RMSEA), the goodness-of-fit index (GFI), the comparative fit index (CFI), and the Tucker-Lewis index (TLI) to examine the goodness of fit of the structural model. GFI, CFI, and TLI values that exceeded .90, $\chi^{2} / d f<3$, and RMSEA values below .08 indicated an acceptable fit (Byrne 2013).

\section{Results}

\subsection{Descriptive Statistics and Correlations among Variables}

Table 1 shows the means, standard deviations, and correlations among all variables. As Table 1 shows, resilience is positively related with positive affect $(r=.38, p<.01)$ and work engagement $(r=.40, p<.01)$. Transformational leadership is positively related with positive affect $(r=.26, p<.01)$ and work engagement $(r=.47, p<.01)$. Positive affect is positively related with work engagement $(r=.45, p<.01)$.

\subsection{Confirmatory Factor Analysis}

To verify the distinctiveness of the four core variables (resilience, transformational leadership, positive affect, and work engagement), we conducted a confirmatory factor analysis (CFA). The measurement model includes four latent constructs and 13 indicators. The CFA results show the four-factor model fits the data well $\left(\chi^{2}=124.80, d f=59, \chi^{2} / d f=2.12\right.$, GFI $=.96$, $\mathrm{CFI}=.98, \mathrm{TLI}=.97, \mathrm{RMSEA}=.05)$. In addition, all indicators load on their respective factors significantly $(p<.001)$. Thus, the CFA results support the construct distinctiveness of resilience, transformational leadership, positive affect, and work engagement.

\subsection{Testing the Mediation Effect with Structural Equation Modeling}

The correlations between resilience and work engagement $(r=.40, p<.01)$ and between transformational leadership and work engagement $(r=.47, p<.01)$ provide preliminary

Table 1 Means, standard deviations, and correlations of the variables of interest

\begin{tabular}{|c|c|c|c|c|c|c|}
\hline & Mean & $\mathrm{SD}$ & 1 & 2 & 3 & 4 \\
\hline Resilience & 3.50 & .54 & 1 & & & \\
\hline $\begin{array}{l}\text { Transformational } \\
\text { leadership }\end{array}$ & 2.66 & .71 & $.19 * *$ & 1 & & \\
\hline Positive affect & 3.98 & .87 & $.38 * *$ & $.26 * *$ & 1 & \\
\hline Work engagement & 3.51 & .58 & $.40 * *$ & $.47 * *$ & $.45 * *$ & 1 \\
\hline
\end{tabular}

$\mathrm{N}=422$

$* p<.05 ; * * p<.01$ 
evidence that resilience and transformational leadership have positive relationships with work engagement.

To test positive affect's mediating effect, we examined the structural model. First, we examined a fully mediating model (Model 1) where resilience and transformational leadership influence work engagement through positive affect. This model has no direct paths from resilience and transformational leadership to work engagement. All fit indexes show a good fit $\left(\chi^{2}=220.96, d f=61, \chi^{2} / d f=3.62\right.$, GFI $=.93$, CFI $=.94$, TLI $=.93$, RMSEA $=.08)$.

Second, we examined a partially mediating model (Model 2). In this model, we added direct paths from resilience to work engagement and from transformational leadership to work engagement. Therefore, Model 1 is nested within Model 2. All fit indexes show a good fit $\left(\chi^{2}=124.80, d f=59, \quad \chi^{2} / d f=2.12, \quad\right.$ GFI $=.96, \quad$ CFI $=.98, \quad$ TLI $=.97$, RMSEA $=.05)$. The difference between Chi squares is more significant for Model 1 than for Model $2\left(\Delta \chi^{2}=96.16, \Delta d f=2, p<.01\right)$. Therefore, we conclude that positive affect partially mediates the relationship between resilience, transformational leadership, and work engagement. Figure 1 shows that the coefficient of the path from resilience to positive affect is significant $(\beta=.19, p<.01)$. The path from transformational leadership to positive affect is significant $(\beta=.18, p<.01)$, as are the coefficients of the path from positive affect to work engagement $(\beta=.27, p<.01)$. In addition, the direct paths from resilience and transformational leadership to work engagement are significant $(\beta=.24$, $p<.01$ and $\beta=.39, p<.01$, respectively).

Furthermore, we used a bootstrap estimation procedure in AMOS to confirm the significance of the mediating effect. Mackinnon and colleagues (2004) asserted that the common estimates of indirect effect usually do not follow the normal suggestion and may cause bias, and the bootstrap method yields the most accurate confidence intervals for indirect effect estimation. Table 2 shows the bootstrap results of the indirect effects. As Table 2 shows, resilience has a significant indirect effect on work engagement via positive affect, and the $95 \%$ confidence interval $(.02, .10)$ excludes zero. Transformational leadership has a significant indirect effect on work engagement via positive affect, and the $95 \%$ confidence interval $(.02, .10)$ excludes zero. The combined results indicate that

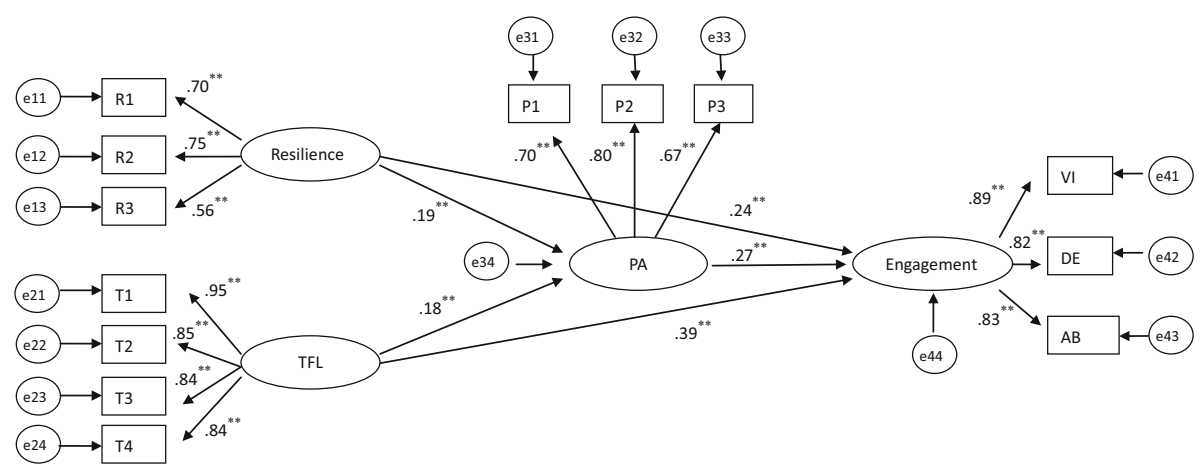

Fig. 1 Mediation model of resilience, transformational leadership, positive affect, and work engagement. Note $\mathrm{N}=422$. Standardized coefficients are reported. TFL transformational leadership, $P A$ positive affect, $V I$ vigor, $D E$ dedication, $A B$ absorption. $R 1-R 3$ are three parcels of resilience. $P 1-P 3$ are three parcels of positive affect. $T 1-T 4$ are four dimensions of transformational leadership. $* p<.05, * * p<.01$ 
Table 2 Direct and indirect effects and $95 \%$ confidence intervals of the mediation model

\begin{tabular}{llll}
\hline Model pathways & Estimated effect & $95 \% \mathrm{CI}$ & \\
\cline { 4 - 4 } & & Lower bounds & Upper bounds \\
\hline Direct effects & & & .33 \\
Resilience $\rightarrow$ positive affect & $.19^{\mathrm{a}}$ & .05 & .30 \\
TFL $\rightarrow$ positive affect & $.18^{\mathrm{a}}$ & .07 & .37 \\
Positive affect $\rightarrow$ work engagement & $.27^{\mathrm{a}}$ & .36 \\
Resilience $\rightarrow$ work engagement & $.24^{\mathrm{a}}$ & .48 \\
TFL $\rightarrow$ work engagement & $.39^{\mathrm{a}}$ & .13 & .10 \\
Indirect effects & & .29 & .09 \\
Resilience $\rightarrow$ positive affect $\rightarrow$ work engagement & $.05^{\mathrm{a}}$ & & .02 \\
TFL $\rightarrow$ positive affect $\rightarrow$ work engagement & $.05^{\mathrm{a}}$ & .02 & \\
\hline
\end{tabular}

Standardized coefficients are reported. $\mathrm{N}=422$. TFL transformational leadership. Empirical $95 \%$ confidence interval does not include zero

positive affect partially mediates the relationships among resilience, transformational leadership, and work engagement.

\section{Discussion}

This study examines the relationships among resilience, transformational leadership, positive affect, and work engagement. As we expected, resilience and transformational leadership are found to be positively associated with work engagement. In addition, we find that positive affect mediates the relationships among resilience, transformational leadership, and work engagement. These results are consistent with previous studies reporting relationships between resilience and positive affect (Tugade et al. 2004), transformational leadership and positive affect (Bono et al. 2007), transformational leadership and work engagement (Zhu et al. 2009), and positive effect of resilience in the workplace (Siu et al. 2009). Our findings bring important theoretical and practical implications to understandings of positive psychology and subjective well-being (SWB).

First, our results show that resilience and transformational leadership act through positive affect to increase work engagement. Work engagement is an emerging concept in positive psychology. Researchers assert that with increasing attention to the effects of positivity in the workplace, it is important to understand what predicts employee positivity (Luthans et al. 2007). To answer that need, our research demonstrates that resilience is a personal resource and transformational leadership is a job resource, and both positively influence work engagement. Although the JD-R model highlights that personal and job resources are key predictors, the underlying mechanism is still unclear. Our study suggests that positive affect is the mediator. When resilient employees face adversity, they can successfully cope, adapt, and recover. In addition, transformational leaders focus on emotional aspects, care about employee needs and provide social support. These factors promote positive affect. Drawing on broaden-and-build theory, positive affect increases a wide range of personal resources and, in turn, enhances work engagement.

Second, this study finds resilience and transformational leadership are positively related to positive affect, a finding that enriches the antecedents of positive affect research. 
Positive affect has received increasing attention in the past decade, and it has been found to be related to lower stress, higher life satisfaction, greater social support, and better mental and physical health (Fredrickson et al. 2008). Indeed, a recent meta-analysis of nearly 300 studies indicates that positive affect generates success and health (Lyubomirsky et al. 2005). However, little research has been conducted on the antecedents of positive affect. Our study suggests that resilience is a personal resource that promotes positive affect. Highly resilient individuals positively cope with and adapt to significant risk or adversity and thus experience and express more positive affect. In addition, we find that transformational leadership can enhance positive affect. Although it is widely believed that workplace factors, particularly leadership, are associated with employee affect, well-being, and stress, little empirical research has documented their effects (Bono et al. 2007). We show that transformational leadership behaviors, such as idealized influence, inspirational motivation, and individualized consideration, create more positive affect.

The findings of the current research also carry practical implications. To promote work engagement, managers may try to recruit and select highly resilient individuals. An alternative way to increase resilience is to provide resilience training for employees. Because transformational leadership shows promise in promoting work engagement, managers may express more transformational leadership behaviors, such as paying attention to employees' different needs, depicting idealized visions, and offering social support. Furthermore, the findings suggest that organizations should employ ways to improve employees' positive affect because doing so will increase satisfaction, improve work engagement, and lead to better organizational effectiveness.

Despite these strengths, our study has some limitations. First, our cross-sectional design makes it difficult to draw causal inferences. Future research may adapt longitudinal surveys or experimental designs to validate the causal relationships in our model. Second, we used a self-report method to collect data. Although the CFA results supported the construct distinctiveness of different measures, common method variance may have artificially influenced our findings (Podsakoff et al. 2003). Future research should measure these constructs from different sources to minimize common method bias. Third, we focused on resilience and transformational leadership as the predictors. It would be worthwhile to investigate other individual attributes and leadership styles in the future. Finally, although sales are a typical sample in IT companies, there still is the question of whether the findings can be generalized to other positions in different settings and industries. Future research on other jobs and organizations should be conducted.

In conclusion, the current study links resilience, transformational leadership, and work engagement, and it identifies positive affect as a mediator. The findings contribute to our understanding of the factors promoting positive affect and work engagement in organizations. We hope the current study encourages future research to explore the relationships among individual differences, leadership, affect, and work engagement.

Acknowledgments This article is supported by the Fundamental Research Funds for the Central Universities, and the Research Funds of Renmin University of China (16XNA006).

\section{References}

Anderson, J. C., \& Gerbing, D. W. (1988). Structural equation modeling in practice. A review and recommended two-step approach. Psychological Bulletin, 103, 411-423. 
Bakker, A. B., Albrecht, S. L., \& Leiter, M. P. (2011). Key questions regarding work engagement. European Journal of Work and Organizational Psychology, 20(1), 4-28.

Bakker, A. B., \& Demerouti, E. (2007). The job demands-resources model: State of the art. Journal of Managerial Psychology, 22, 309-328.

Bakker, A. B., \& Demerouti, E. (2008). Towards a model of work engagement. Career Development International, 13, 209-223.

Bass, B. M. (1985). Leadership and performance beyond expectations. New York: Free Press.

Bono, J. E., Jackson Foldes, H., Vinson, G., \& Muros, J. P. (2007). Workplace emotions: The role of supervision and leadership. Journal of Applied Psychology, 92, 1357-1367.

Brislin, R. W. (1980). Translation and content analysis of oral and written material. In H. C. Triandis \& J. W. Berry (Eds.), Handbook of cross-cultural psychology (Vol. 2-Methodology, pp. 349-444). Boston: Allyn \& Bacon.

Byrne, B. M. (2013). Structural equation modeling with AMOS: Basic concepts, applications, and programming. Abingdon: Routledge.

Crawford, E. R., Lepine, J. A., \& Rich, B. L. (2010). Linking job demands and resources to employee engagement and burnout: A theoretical extension and meta-analytic test. Journal of Applied Psychology, 95, 834-848.

Diener, E. D. (2000). Subjective well-being: The science of happiness and a proposal for a national index. American Psychologist, 55(1), 34-43.

Fredrickson, B. L. (2001). The role of positive emotions in positive psychology: The broaden-and-build theory of positive emotions. American Psychologist, 56, 218-226.

Fredrickson, B. L., Cohn, M. A., Coffey, K. A., Pek, J., \& Finkel, S. M. (2008). Open hearts build lives: Positive emotions, induced through loving-kindness meditation, build consequential personal resources. Journal of Personality and Social Psychology, 95, 1045-1062.

Fredrickson, B. L., Tugade, M. M., Waugh, C. E., \& Larkin, G. R. (2003). What good are positive emotions in crises? A prospective study of resilience and emotions following the terrorist attacks on the United States on September 11th, 2001. Journal of Personality and Social Psychology, 84(2), 365-376.

Hu, L. T., \& Bentler, P. M. (1999). Cut off criteria for fit indexes in covariance structure analysis: Conventional criteria versus new alternatives. Structural Equation Modeling, 6, 1-55.

Luthans, F. (2002). The need for and meaning of positive organizational behavior. Journal of Organizational Behavior, 23, 695-706.

Luthans, F., Avolio, B. J., Avey, J. B., \& Norman, S. M. (2007). Positive psychological capital: Measurement and relationship with performance and satisfaction. Personnel Psychology, 60, 541-572.

Lyubomirsky, S., King, L., \& Diener, E. (2005). The benefits of frequent positive affect: Does happiness lead to success? Psychological Bulletin, 131, 803-855.

MacKenzie, S. B., Podsakoff, P. M., \& Rich, G. A. (2001). Transformational and transactional leadership and salesperson performance. Journal of Academy of Marketing Science, 29, 115-134.

Mackinnon, D. P., Lockwood, C. M., \& Williams, J. (2004). Confidence limits for the indirect effect: Distribution of the product and resampling methods. Multivariate Behavioral Research, 39, 99-128.

Masten, A. S. (2001). Ordinary magic: Resilience processes in development. American Psychologist, 56, 227-239.

Peterson, C. (2006). A primer in positive psychology. New York: Oxford University Press. Burnout and physical and mental health among Swedish healthcare workers. Journal of Advanced Nursing, 62, 84-95.

Podsakoff, P. M., MacKenzie, S. B., Lee, J. Y., \& Podsakoff, N. P. (2003). Common method biases in behavioral research: A critical review of the literature and recommended remedies. Journal of Applied Psychology, 88, 879-903.

Podsakoff, P. M., MacKenzie, S. B., Moorman, R. H., \& Fetter, R. (1990). Transformational leader behaviors and their effects on followers' trust in leader, satisfaction, and organizational citizenship behaviors. The Leadership Quarterly, 1, 107-142.

Schaufeli, W. B., \& Bakker, A. B. (2004). Job demands, job resources, and their relationship with burnout and engagement: A multi-sample study. Journal of Organizational Behavior, 25, 293-315.

Schaufeli, W. B., Salanova, M., González-Romá, V., \& Bakker, A. B. (2002). The measurement of engagement and burnout: A two sample confirmatory factor analytic approach. Journal of Happiness Studies, 3, 71-92.

Seligman, M. E. P., \& Csikszentmihalyi, M. (2000). Positive psychology progress: Empirical validation of interventions. American Psychologist, 55(1), 5-14.

Seligman, M. E. P., Steen, T. A., Park, N., \& Peterson, C. (2005). Positive psychology progress. American Psychologist, 60(5), 410-421. 
Siu, O. L., Hui, C. H., Phillips, D. R., Lin, L., Wong, T., \& Shi, K. (2009). A study of resiliency among Chinese Health Care workers: Capacity to cope with workplace stress. Journal of Research in Personality, 43(5), 770-776.

Sonnentag, S., Mojza, E. J., Binnewies, C., \& Scholl, A. (2008). Being engaged at work and detached at home: A week-level study on work engagement, psychological detachment, and affect. Work and Stress, 22, 257-276.

Thoresen, C. J., Kaplan, S. A., Barsky, A. P., Warren, C. R., \& de Chermont, K. (2003). The affective underpinnings of job perceptions and attitudes: A meta-analytic review and integration. Psychological Bulletin, 129, 914-945.

Tugade, M. M., Fredrickson, B. L., \& Barrett, L. F. (2004). Psychological resilience and positive emotional granularity. Journal of Personality, 72, 1161-1190.

Watson, D., Clark, L. A., \& Tellegen, A. (1988). Development and validation of brief measures of positive and negative affect: The PANAS scales. Journal of Personality and Social Psychology, 54(6), 1063-1070.

Watson, D., Wiese, D., Vaidya, J., \& Tellegen, A. (1999). The two general activation systems of affect: Structural findings, evolutionary considerations, and psychobiological evidence. Journal of Personality and Social Psychology, 76, 820-838.

Xanthopoulou, D., Bakker, A. B., Demerouti, E., \& Schaufeli, W. B. (2007). The role of personal resources in the job demands-resources model. International Journal of Stress Management, 14, 121-141.

Yan, X., \& Su, J. (2013). Core self-evaluation mediators of the influence of social support on job involvement in hospital nurses. Social Indicator Research, 113, 299-306.

Zhu, W., Avolio, B. J., \& Walumbwa, O. (2009). Moderating role of follower characteristics with transformational leadership and follower work engagement. Group and Organization Management, 34, 590-619. 